\title{
Differentiation of Claviceps purpurea in Axenic Culture
}

\author{
By P. G. MANTLE AND L. J. NISBET \\ Biochemistry Department, Imperial College, London $\mathrm{SW}_{7} 2 \mathrm{AZ}$
}

(Received 9 June 1975)

\begin{abstract}
SUMMARY
The growth form of a strain of Claviceps purpurea in axenic culture has been controlled by the amino nitrogen source. Within the pairs asparagine/aspartic acid or glutamine/glutamic acid the amide promoted sphacelial growth of the colony whereas the acid supported differentiation of plectenchymatic sclerotial tissue and synthesis of ergot alkaloids. Sclerotial colonies showed purple pigmentation. The mycelium had a greater lipid content, rich in ricinoleic acid, and sporulation was much less than in sphacelial colonies. Changes in the relative distribution of amino acids between the free and peptidyl components of the cells was most marked with respect to lysine; growth on asparagine resulted in more than half remaining free, whereas less than $10 \%$ remained free on aspartic acid. Lysine supplied exogenously as a nitrogen source did not promote sclerotial differentiation. Frequent transfers to fresh medium of colonies grown on dialysis membrane accentuated the extent of sphacelial or sclerotial growth; four transfers during an 18-day growth period yielded mycelia with an alkaloid content $(0.4 \%$, w/w) similar to that of parasitic ergot sclerotia. Asparagine and glutamine were taken up more rapidly from liquid media than their corresponding acids, but each acid exerted a dominant effect over the amide, in a mixture providing equivalent nitrogen, resulting in differentiation from sphacelial to sclerotial growth analogous to that occurring during parasitism. The apparently greater $(\mathrm{w} / \mathrm{w})$ proportion of total amino acids in sphacelial mycelia than in sclerotial mycelia mainly reflected the lower lipid content of these tissues, but this factor was insufficient to account for the persistence of a significant proportion of the total lysine amongst the free amino acids. The promotion of sclerotial growth by aspartic and glutamic acids was not confined solely to the experimental strain of the fungus. Although some isolates failed to differentiate into plectenchymatic mycelia on these nitrogen sources, the extent of their sphacelial growth, as indicated by the degree of sporulation, was always much reduced with respect to that promoted by asparagine.
\end{abstract}

\section{INTRODUCTION}

Fermentation of the ergot fungus Claviceps purpurea is a potential source of ergot alkaloids, obviating the more traditional technology involving parasitism of rye. Although research groups in many parts of the world have for many years worked on the problems associated with production of alkaloids by axenic culture, the development of economically successful processes using this organism has presented considerable problems. Very few strains of the fungus have given useful yields of alkaloids (for review, see Mantle, 1975). It has been proposed (Mantle \& Tonolo, I968; Mantle, 1969 $a, b$ ) that mycelial differentiation into cells resembling those of parasitic ergot sclerotia is a prerequisite for the production of ergot alkaloids by $C$. purpurea. Apart from the morphological indications of sclerotial tissues, the most reliable diagnostic biochemical feature is that the abundant triglyceride oil of sclerotial hyphae, much greater than is normally present in sphacelial hyphae, is of a 
unique type rich in ricinoleic acid (Morris \& Hall, 1966; Mantle, Morris \& Hall, 1969). The value of ricinoleate as a diagnostic tool has been confirmed by Waiblinger \& Groger (1972).

There is a sharp distinction between the behaviour of the fungus as a parasite, when the differentiation from sphacelial to sclerotial growth is a regular phase in the cycle of parasitic events, and that which occurs in axenic culture when the fungus almost always persists in the sphacelial form. An understanding of the factors controlling initiation of the sclerotial growth form may, therefore, facilitate an improvement in the prospects for fermentation production of ergot alkaloids by $C$. purpurea.

This paper describes the control of sphacelial/sclerotial growth by the form in which an amino nitrogen source is presented to the fungus.

\section{METHODS}

Media. Medium A (modified from Stoll et al., I957) had the following composition (g/l distilled water): sucrose, I00; L-asparagine, $10 ; \mathrm{Ca}\left(\mathrm{NO}_{3}\right)_{2} \cdot 4 \mathrm{H}_{2} \mathrm{O}, \mathrm{I} ; \mathrm{KH}_{2} \mathrm{PO}_{4}, 0 \cdot 25$; $\mathrm{MgSO}_{4} .7 \mathrm{H}_{2} \mathrm{O}, 0.25 ; \mathrm{KCl}, 0.125 ; \mathrm{FeSO}_{4} .7 \mathrm{H}_{2} \mathrm{O}, 0.033 ; \mathrm{ZnSO}_{4} .7 \mathrm{H}_{2} \mathrm{O}, 0.027 ;$ L-cysteine hydrochloride, $0.0 \mathrm{I}$; yeast extract (Oxoid), $0 . \mathrm{r} ; \mathrm{pH}$ adjusted to 5.2 with concentrated $\mathrm{NaOH}$; sterilized at $\mathrm{I} 10^{\circ} \mathrm{C}$ for $20 \mathrm{~min}$. Solid media contained $2 \%(\mathrm{w} / \mathrm{v})$ Oxoid agar. For liquid cultures, I00 $\mathrm{ml}$ medium was dispensed into $500 \mathrm{ml}$ Erlenmeyer flasks fitted with polythene foam plugs.

Amino-nitrogen media consisted of medium A minus $\mathrm{Ca}\left(\mathrm{NO}_{3}\right)_{2} \cdot 4 \mathrm{H}_{2} \mathrm{O}$, cysteine hydrochloride and yeast extract, and with the addition of $\mathrm{L}$-asparagine $(5 \mathrm{~g} / \mathrm{l})$ or other L-amino acids in amounts supplying equivalent nitrogen, e.g. Io g aspartic acid/l. Heat labile amino acids were sterilized separately by filtration and added to sterile, cold medium.

Medium B (modified from Amici et al., I969) had the following composition ( $\mathrm{g} / 1$ distilled water): sucrose, I00; citric acid, Iо; $\mathrm{Ca}\left(\mathrm{NO}_{3}\right)_{2} .4 \mathrm{H}_{2} \mathrm{O}, \mathrm{I} ; \mathrm{KH}_{2} \mathrm{PO}_{4}, 0.5 ; \mathrm{MgSO}_{4} \cdot 7 \mathrm{H}_{2} \mathrm{O}$, $0 \cdot 25 ; \mathrm{KCl}, 0 \cdot 12 ; \mathrm{FeSO}_{4} \cdot 7 \mathrm{H}_{2} \mathrm{O}, 0.007 ; \mathrm{ZnSO}_{4} \cdot 7 \mathrm{H}_{2} \mathrm{O}, 0 \cdot 006 ; \mathrm{pH}$ adjusted to $5 \cdot 2$ with ammonia; sterilized at $110{ }^{\circ} \mathrm{C}$ for $20 \mathrm{~min}$. This medium (100 $\mathrm{ml}$ per $500 \mathrm{ml}$ Erlenmeyer flask) was used as a seed stage, which was subsequently used to inoculate production stage medium $\mathrm{C}$ for evaluation of alkaloid production in submerged culture.

Medium C (modified from Amici et al., 1969) was as medium B except that it contained $300 \mathrm{~g}$ sucrose, $\mathrm{I} 5 \mathrm{~g}$ citric acid and I g yeast extract/l.

Shaken-flask liquid culture. Medium A slant cultures (I 4 days old) were scraped to remove mycelium or spores which were then used to inoculate medium B. Flasks were incubated at $25^{\circ} \mathrm{C}$ on a rotary shaker (200 rev./min and $9 \mathrm{~cm}$ eccentric throw) for 7 days, and the mycelium then transferred (10 \%, v/v) to medium $\mathrm{C}$ for a further $\mathrm{I} 4$ days when the filtrate was analysed for alkaloid. Mycelium was filtered, washed, freeze-dried and stored at $-20{ }^{\circ} \mathrm{C}$ pending further analysis. For estimation of amino acid uptake, samples were taken at selected intervals and the supernatants from duplicate flasks were stored at $-20^{\circ} \mathrm{C}$ before autoanalysis.

Liquid cultures in amino nitrogen media. A spore suspension prepared from a I4-day-old agar slope culture was inoculated ( $\mathrm{I} \mathrm{ml}$ containing $10^{6}$ spores) into flasks of amino acid media which were subsequently incubated at $25^{\circ} \mathrm{C}$ on a rotary shaker for $\mathrm{I} 4$ days.

Agar culture on amino nitrogen media. Approximately $10^{5}$ spores, suspended in a drop of distilled water, were inoculated on to the centre of agar plates which were then incubated at $25{ }^{\circ} \mathrm{C}$ for $2 \mathrm{I}$ days.

Culture on a semi-permeable membrane. Sterile discs of cellophane dialysis membranes (Technicon Ltd) were spread over partly-dried agar plates. A drop of spore suspension was 
placed at the centre of the membrane and the plates incubated at $25^{\circ} \mathrm{C}$ for I 8 days. Colonies on membranes could readily be transferred aseptically, when required, to fresh moist agar media. At each sampling stage randomly selected colonies were removed intact from the membranes, combined in triplicate, homogenized, freeze-dried and stored at $-20^{\circ} \mathrm{C}$. Analysis of the chemical constituents was done on the combined sample.

Preparation of single spore isolates. Spores from mature agar cultures were spread (about $\mathrm{IO}^{3}$ spores/plate) on to medium $\mathrm{A}$ agar in Petri dishes and incubated at $25^{\circ} \mathrm{C}$ until germ tubes $(60 \mu \mathrm{m}$ long) had formed $(24 \mathrm{~h})$, whereupon individual germinated spores were removed with a thin wire needle and transferred to fresh medium A agar (4 spores/plate), and incubated similarly for a further 7 days.

Alkaloid analysis. The alkaloid concentration in the culture filtrate was determined, after appropriate dilution, by colorimetric measurement of the blue colour formed by reaction with Van Urk reagent (Mantle, 1967) using an EEL colorimeter at $570 \mathrm{~mm}$. The extinctions were compared with a standard curve for ergotamine tartrate solutions in the range Io to I00 $\mu \mathrm{g} / \mathrm{ml}$. Accurate determinations of concentrations as low as $15 \mu \mathrm{g}$ alkaloid/ml filtrate could be obtained.

Alkaloid determinations on freeze-dried mycelia followed the method of Corbett, Dickerson \& Mantle (1974).

Mixtures of alkaloids were resolved by thin-layer chromatography using the system described by McLaughlin, Goyan \& Paul (I964).

Mycelial dry weight analysis. The mean dry weights of mycelia were based on freeze-dried weights of between 5 and 9 replicate samples, the larger number of replicates being used for young colony stages.

Mycelial lipid analysis. Part of the mycelial lipid had been extracted into ether during the alkaloid extraction. Residual lipid was therefore extracted with chloroform-methanol (2:I) (Corbett et al., 1974) and the lipid from both sources combined.

The extracted lipid was saponified with $\mathrm{KOH}(\mathrm{IO} \%$, w/v) in methanol and the resulting fatty acids were methylated with diazomethane. This was found to be preferable to the technique using boron trifluoride $(14 \%, w / v)$ in methanol on account of a better yield of ricinoleate. The fatty acid methyl esters were separated and quantified by gas-liquid chromatography (Pye I04 chromatograph) using argon as a carrier gas and a Free Fatty Acid Phase (5\%; Phase Separations, Wales) liquid phase on chromosorb W (acid-washed dimethyl silate) support in a $5 \mathrm{ft}(\mathrm{I} \cdot 5 \mathrm{~m})$ glass column. This system facilitated determinations of both ricinoleic and all other fatty acids by the use of the appropriate column temperature. Ricinoleate gave a peak of normal distribution at $240{ }^{\circ} \mathrm{C}$ with a retention time of $9 \mathrm{~min}$. At $200{ }^{\circ} \mathrm{C}$ the other fatty acid esters became adequately resolved. Concentrations of fatty acids were determined by comparison with standards (Sigma), and are given as $\%(w / w)$ of the total triglyceride fatty acids.

Thin-layer chromatographic separation of methyl esters of fatty acids (Morris \& Wharry, I965) was also employed, particularly for qualitative confirmation of methyl ricinoleate.

Amino acid analysis. Approximately $30 \mathrm{mg}$ of freeze-dried mycelium was extracted for I h successively with $10 \mathrm{ml}$ of $\mathrm{I} \mathrm{M}$-perchloric acid, $\mathrm{Io} \mathrm{ml}$ of $0.2 \mathrm{M}$-perchloric acid and $2 \mathrm{ml}$ distilled water. After alkaline $(\mathrm{KOH})$ precipitation of perchlorate the supernatant $(\mathrm{pH} 5.5)$ from each sample was passed through Zeocarb 225 cation-exchange resin (200 mesh, $\mathrm{H}^{+}$form) to absorb the amino acids which were subsequently eluted from the column with dilute ammonium hydroxide solution, taken to dryness, resuspended in an appropriate volume (6 to $12 \mathrm{ml}$ ) of $0.025 \mathrm{M}-\mathrm{HCl}$ and assayed by an automated method (Thomas, I970).

The residual pellet of mycelium was treated with $15 \mathrm{ml}$ of $6 \mathrm{M}-\mathrm{HCl}$ and refluxed for $24 \mathrm{~h}$, 
after which the supernatant was taken to dryness, resuspended in $0.025 \mathrm{M}-\mathrm{HCl}$ and assayed as above. This was designated the 'peptidyl' amino acid fraction.

The uptake of amino acid nitrogen sources from liquid media was calculated as a percentage of the initial concentration, as assayed by the method of Thomas (1970), and represented the mean of two determinations.

\section{RESULTS}

\section{Origin of experimental organism}

A strain of $C$. purpurea, designated strain $17 / 3$, which was first isolated from a sclerotium on Alopecurus myosuroides in 1960 and had since been used in several studies (Corbett et al., 1974; Mantle \& Nisbet, I976), was selected for the present studies, as it had the distinction of being (in 1960) one of the first strains to give good yields (about $300 \mu \mathrm{g} / \mathrm{ml}$ ) of cyclic tripeptide ergolene alkaloids in axenic culture and also retained pathogenicity against rye on which it produced characteristically long sclerotia (Corbett et al., 1974; Mantle \& Nisbet, 1976). Reselection of this strain resulted in a sub-strain, designated strain 29/4, which, when grown in axenic culture on medium $A$ in which asparagine was the principal nitrogen source, confirmed the production of a sclerotial-like growth form. This strain also produced sclerotial mycelium and alkaloid $(380 \mu \mathrm{g} / \mathrm{ml})$ in submerged culture in medium $\mathrm{C}$, but lost this capacity after repeated subculture, and persisted in a freely-sporulating sphacelial form on agar media. The 'degenerated' form, designated strain 29/4D, was grown in submerged culture in a range of $\mathrm{I} 8$ common amino acids as sole nitrogen sources. Differentiation of mycelial hyphae into a form morphologically resembling the cells of natural ergot sclerotial tissue, and containing dark purple pigmentation, occurred in $\gamma$-aminobutyric acid $(\gamma-\mathrm{Aba})$, alanine, histidine, $\beta$-phenylalanine, valine, serine and both aspartic and glutamic acids. The latter pair also supported a good rate of growth similar to that occurring in liquid media containing the corresponding amides (asparagine and glutamine), in which the $\mathrm{pH}$ value of the broth also remained in the range 5.0 to 6.0 , although mycelial growth persisted in the sphacelial form and yielded many spores (about $10^{8} / \mathrm{ml}$ ). The triglyceride oil contents of the two mycelial forms were quantitatively similar (about $10 \%, w / w)$, but the distribution in sclerotial-like hyphae was diffuse whereas sphacelial hyphae contained discrete lipid vesicles. Fatty acid compositions of the triglyceride oils showed large differences in the amount of ricinoleic acid; aspartic acid-grown mycelial oil contained $27 \%(w / w)$ ricinoleate, whereas that yielded in asparagine medium contained only a trace ( $\mathrm{r} \%, \mathrm{w} / \mathrm{w})$.

Growth of strain 29/4D in a liquid medium in which tryptophan $(0.5 \%, \mathrm{w} / \mathrm{w})$ was the sole nitrogen source gave a seed stage culture which when transferred (10 \%, v/v, whole broth) to similar medium, but in which the nitrogen source was asparagine or ammonium, produced alkaloid yields of up to $700 \mu \mathrm{g} / \mathrm{ml}$. The principal alkaloids were ergotoxine and ergosine, together with traces of their iso-lysergic acid derivative isomers. The mycelium consisted of short fragmented hyphae with frequent septa and large brown-purple pigmented cells containing $29 \%$, w/w of triglyceride oil rich $(26 \%, \mathrm{w} / \mathrm{w})$ in ricinoleate. More marked differences in the response of strain 29/4D to a wide range of amino nitrogen sources were observed in agar cultures.

A predominantly sclerotial colony was evident within 7 days on alanine, glycine, serine and valine but the growth rate was not as great as that produced on aspartic or glutamic acids. The existence of sclerotial tissue in colonies grown on arginine, isoleucine, $\gamma$-aminobutyric acid, histidine and $\beta$-phenylalanine was only evident after about 3 weeks' growth. $\beta$-Alanine, leucine, lysine, threonine and tryptophan gave only a sparce sphacelial growth whereas 


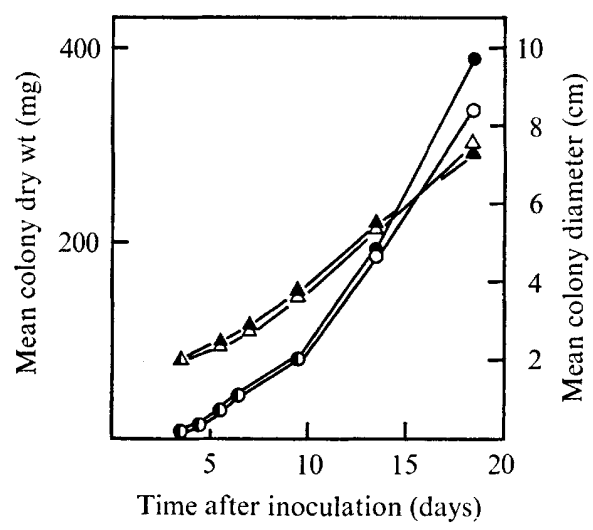

Fig. I

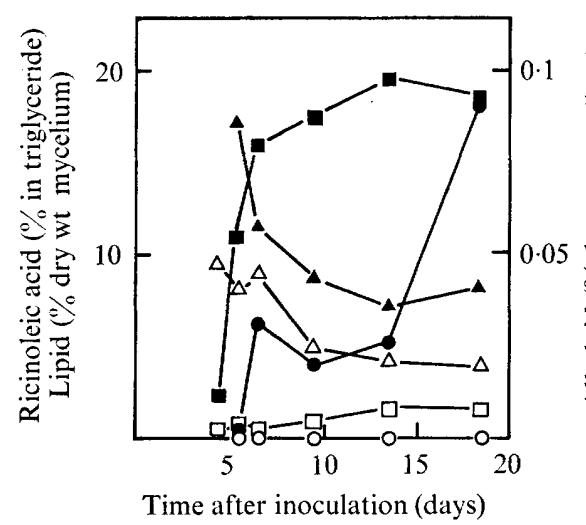

Fig. 2

Fig. I. Dry weight $(O, \bullet)$ and diameter $(\triangle, \Delta)$ of colonies of $C$. purpurea strain 29/4D3 grown on membranes over asparagine (open symbols) and aspartic acid (closed symbols) agar media. Standard deviations for both parameters are in the range 2 to $5 \%$.

Fig. 2. Alkaloid $(\bigcirc, \bullet)$, lipid $(\triangle, \Delta)$ and ricinoleate $(\square, \square)$ content of mycelia of $C$. purpurea strain 29/4D3 grown on membranes over asparagine (open symbols) and aspartic acid (closed symbols) agar media.

asparagine and glutamine supported profuse sporulation on a colony having a growth rate similar to that on aspartic and glutamic acids.

Thus the divergent responses to the pairs asparagine/aspartic acid and glutamine/glutamic acid provided the basis for the present investigation. Consequently, in order to obtain a pure homokaryotic strain, forty isolates were obtained from single uni-nucleate conidia. Thirtynine isolates gave the characteristic sclerotial growth on aspartic acid and sphacelial growth on asparagine and one of these, designated strain 29/4D3, was used for all subsequent studies.

\section{Performance of undisturbed growth on agar media}

Growth. Comparison of the total dry weight and colony diameter of cultures (Fig. I) showed an identical rate of growth across agar containing either asparagine or aspartic acid and similar dry matter accumulation, which only in the last week of growth revealed a slightly greater value in the sclerotial mycelia grown on aspartic acid.

Spore production. Sporulation on asparagine increased from $2 \times 10^{5} / \mathrm{mg}$ freeze-dried mycelium after $5 \frac{1}{2}$ days to $8.9 \times 10^{6} / \mathrm{mg}$ after $18 \frac{1}{2}$ days (Table I). On aspartic acid a ring of spores was produced on the colony at the circumference position of a 7 -day-old colony. This feature had not been evident in preliminary studies when the mycelium was in direct agar contact. Spore production was delayed for about one day relative to asparagine-grown colonies, giving $\mathrm{I} \times \mathrm{IO}^{4}$ spores/mg after $6 \frac{1}{2}$ days which increased to a maximum of $2 \cdot 6 \times 10^{6} / \mathrm{mg}$ by $13 \frac{1}{2}$ days.

Spores produced on asparagine (I $2 \cdot 2 \times 4.6 \mu \mathrm{m}$; length to breadth ratio $2 \cdot 7: \mathrm{I})$ were ellipsoid and contained bipolar lipid vesicles.

In contrast, aspartic acid spores $(\mathrm{I} 0.6 \times 6.8 \mu \mathrm{m}$; length to breadth ratio $\mathrm{I} \cdot 4: \mathrm{I})$ were oval with more evenly distributed lipid. Thus, while the spores differed in shape, size and lipid distribution, the fatty acid profiles of the spore lipids were relatively similar; the apparent incidence of ricinoleate $(3.5 \%, \mathrm{w} / \mathrm{w})$ in the aspartic acid-grown spores may be an artefact due to superficial contamination of spores with the ricinoleate-rich oil which is commonly found extracellularly amongst plectenchymatic hyphae of ergot sclerotial cells. 
Table I. Sporulation and triglyceride fatty acid compositions of mycelia of $C$. purpurea strain 29/4D3 grown on membranes over asparagine and aspartic acid agar media

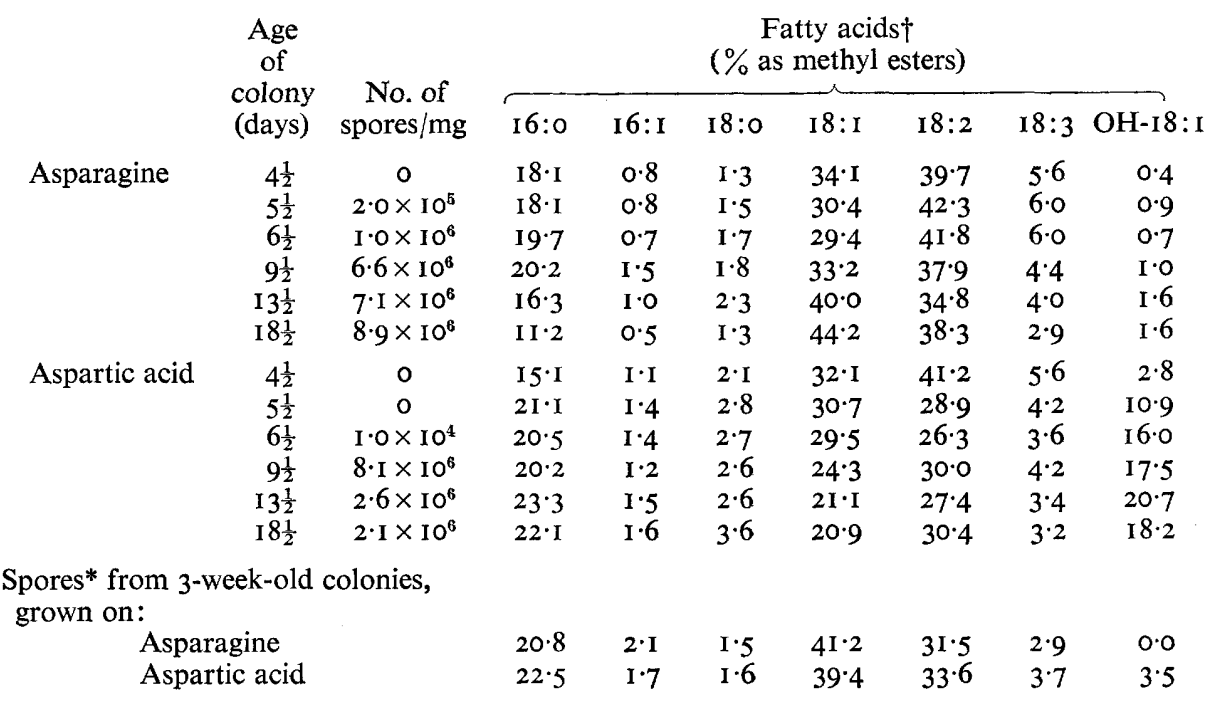

* Used as inoculum ( $4 \% \mathrm{w} / \mathrm{w}$, lipid) for above experiment.

$\dagger$ 16:0, Heptadecanoic acid; I6: I, cis-9-heptadecenoic acid; 18:0, octadecanoic acid; I8: I, cis-9-octadecenoic acid; $18: 2$, cis-9,12-octadecadienoic acid; 18:3, cis-9,12,15-octadecatrienoic acid; OH-18: I, D-1 2-hydroxy-cis-9-octadecenoic acid.

Alkaloid. Alkaloid was not detected in the asparagine-grown colonies but accumulated in aspartic acid mycelia (Fig. 2). Alkaloid first appeared after $5 \frac{1}{2}$ days, one day after the first signs of purple pigmentation. From $6 \frac{1}{2}$ to $13 \frac{1}{2}$ days, the amount of alkaloid did not appear to increase, probably due to the concurrent formation of non-alkaloid synthesizing biomass in the form of spores, but thereafter markedly increased to $0.09 \%(w / w)$. Thin-layer chromatography revealed that the alkaloids consisted almost exclusively of ergotoxine, ergosine and their isomers, and this alkaloid spectrum was similar at all stages of colony growth.

Lipid. The lipid content of spores was $4 \%(w / w)$. This is therefore the minimum lipid concentration of the cells which were used to initiate the colonies.

After $4 \frac{1}{2}$ days, the mycelial lipid on both media was at its highest concentration but thereafter declined, probably due to the production of spores whose lipid content was much lower than that of hyphae. At all times the aspartic acid-grown colonies contained about twice the lipid of the mycelia grown on asparagine.

The triglyceride oil extracted from asparagine mycelia contained about $\mathrm{I} \%(\mathrm{w} / \mathrm{w})$ ricinoleate and large quantities $(\sim 40 \%, \mathrm{w} / \mathrm{w})$ of linoleate (Table $\mathrm{I})$. Oleate increased during growth whereas palmitate decreased. In contrast on aspartic acid, ricinoleate increased sharply from about $3 \%$ after $4 \frac{1}{2}$ days to about $20 \%$ in mature colonies (Table I, Fig. 2). The increase in the concentration of ricinoleate was compensated by a corresponding decrease in the amounts of linoleate and oleate.

Amino acids. The most marked changes in the 'free' amino acids extracted from mycelia concerned lysine, alanine and glutamic acid (Table 2). The lysine content of colonies on asparagine increased sharply between $4 \frac{1}{2}$ days $\left(5 . \mathrm{I} \mathrm{mg} / \mathrm{g}\right.$ dry wt) and $9 \frac{1}{2}$ days $(22.4 \mathrm{mg} / \mathrm{g}$ dry $w t)$, coincident with spore production, while in the mycelia on aspartic acid there was only 


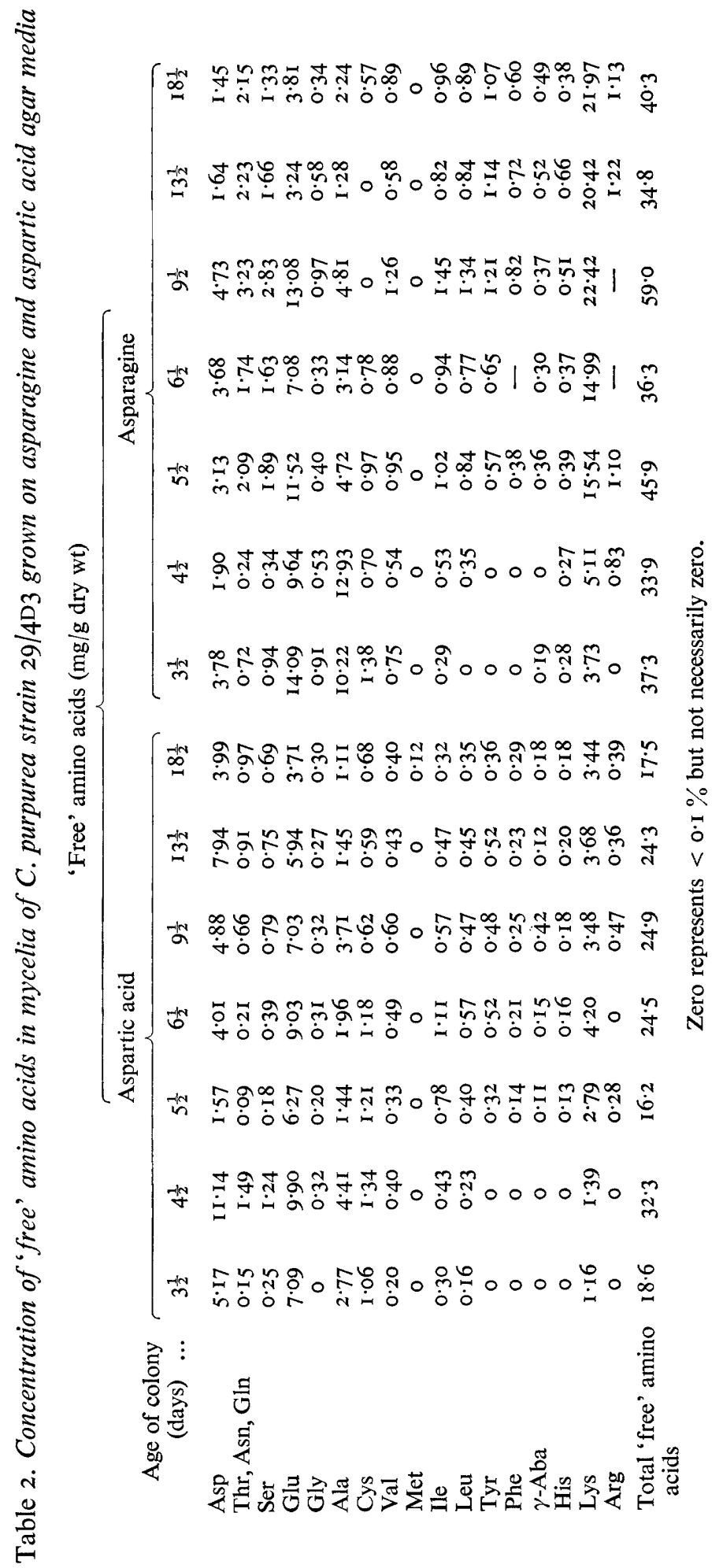




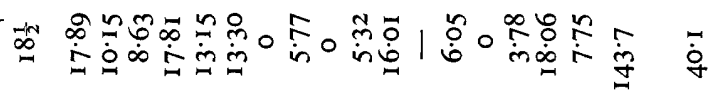

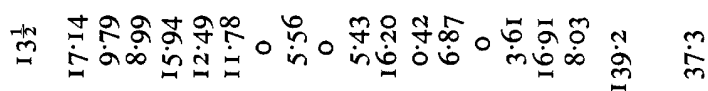

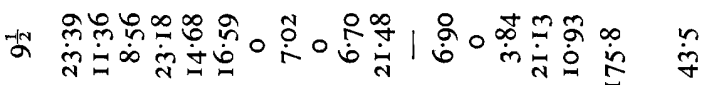

营

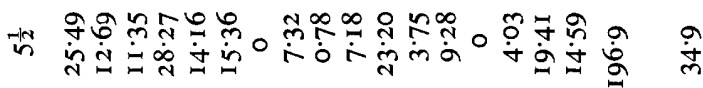

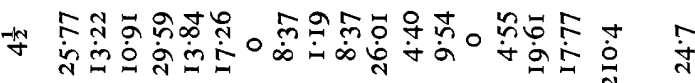

-

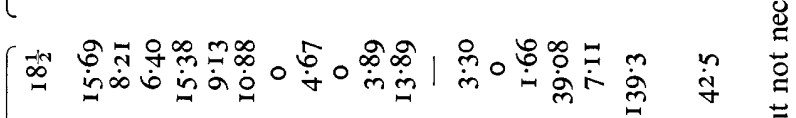

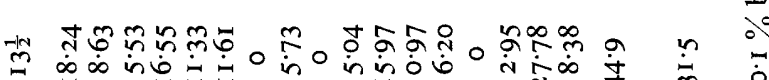

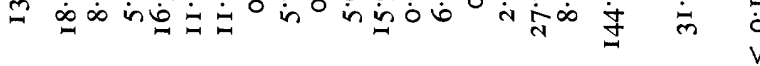

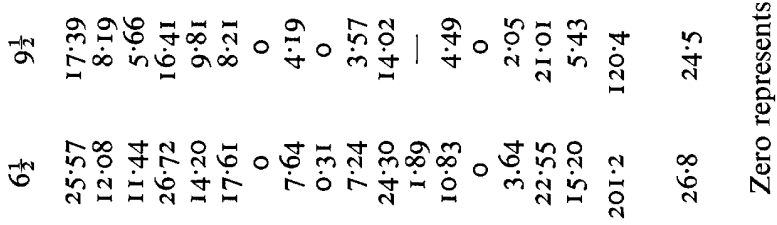

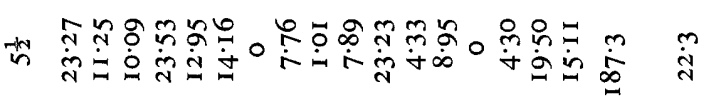

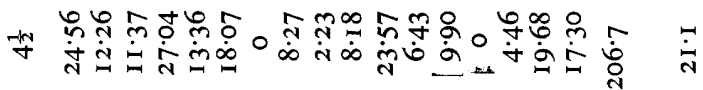

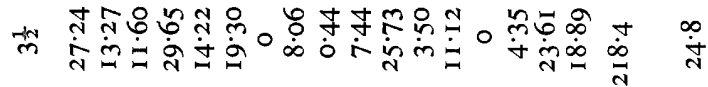




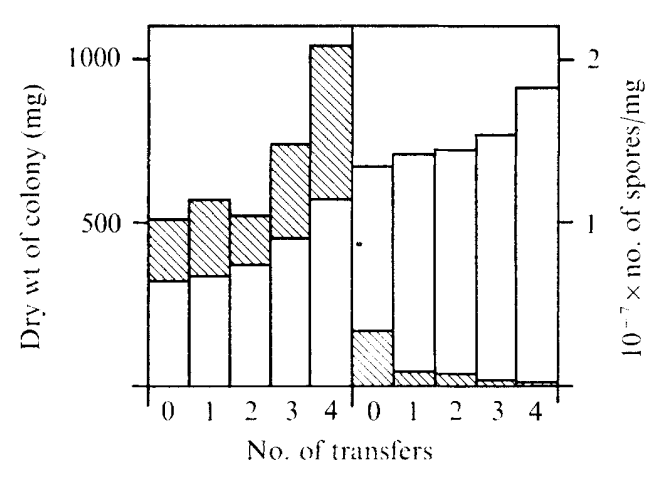

Fig. 3

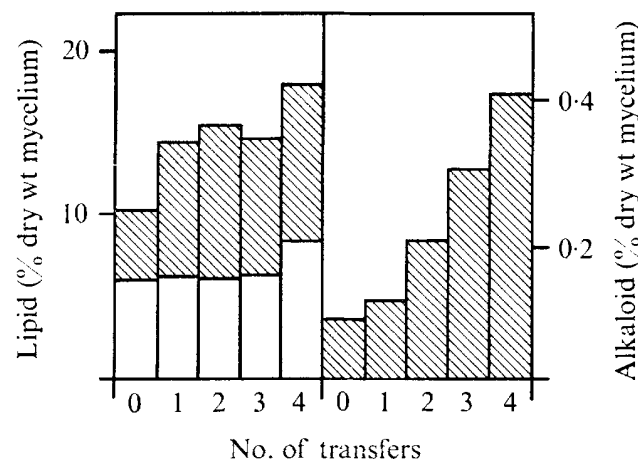

Fig. 4

Fig. 3. Dry weight and spore production of I 8-day-old mycelia of $C$. purpurea strain 29/4D3 transferred to fresh asparagine ( $\square$ ) or aspartic acid ( $\mathbb{S}$ ) media.

Fig. 4. Lipid and alkaloid production by 18-day-old mycelia of $C$. purpurea strain 29/4D3 transferred to fresh asparagine ( $\square$ ) or aspartic acid ( $\$$ ) media.

a slight increase in lysine. Initially the alanine composition of asparagine mycelia decreased from age $4 \frac{1}{2}$ days ( $12.9 \mathrm{mg} / \mathrm{g}$ dry wt) to $5 \frac{1}{2}$ days $(4.7 \mathrm{mg} / \mathrm{g}$ dry wt), whereas on aspartic acid the alanine concentration remained low throughout ( $\mathrm{r}$ to $4 \mathrm{mg} / \mathrm{g}$ dry wt). With both asparagine and aspartic acid colonies, the glutamic acid content declined over the period of the experiment although the decrease was larger on asparagine. The total 'free' amino acid content of colonies grown on asparagine was generally much greater than on aspartic acid.

The predominant 'peptidyl' amino acids (mainly components of the protein, Table 3) were lysine, glutamic acid, aspartic acid, leucine and alanine. The lysine content of mycelia on asparagine decreased from 28.9 to I $8 \cdot \mathrm{I} \mathrm{mg} / \mathrm{g}$ dry wt over the period of growth, while the converse occurred on aspartic acid $(23.6$ to $39.1 \mathrm{mg} / \mathrm{g}$ dry wt). The concentrations of glutamic acid, aspartic acid, leucine and alanine declined coincident with the decrease in total protein in colonies on both asparagine and aspartic acid.

The total ('free' + 'peptidyl') lysine concentration in mycelia on asparagine and aspartic acid media increased during growth to achieve similar values ( 40 and $42 \mathrm{mg} / \mathrm{g}$ dry wt, respectively) which are the product of the contrasting changes in 'free' and 'peptidyl' lysine components (Table 3).

\section{Effect of frequent transfer of colonies to fresh agar medium}

Colonies of strain 29/4D3 grown on membranes were transferred (Fig. 3) to fresh aspartic acid and asparagine media and the dry weight, alkaloid, lipid, ricinoleic acid and spore production were determined for colonies transferred $0, \mathrm{I}, 2,3$ and 4 times during an 18 day growth period.

Growth. The dry weight of the most frequently transferred asparagine colonies increased by only $60 \%$ over the control, whereas colonies most frequently transferred on aspartic acid accumulated twice as much dry weight as their controls.

Spore production. The band of sporulation, characteristic of colonies grown undisturbed on membranes over aspartic acid medium, was apparently eliminated and the overall number of spores associated with the colony was reduced by up to $95 \%$ of the control value, when colonies were transferred to fresh agar (Fig. 3). In contrast, sporulation of asparagine colonies increased with frequency of transfer up to a maximum increase of $35 \%$. 
Table 4. Triglyceride fatty acid compositions of colonies of C. purpurea strain 29/4D3 transferred to fresh asparagine or aspartic acid media

\begin{tabular}{|c|c|c|c|c|c|c|c|c|}
\hline \multirow[b]{2}{*}{ Medium } & \multirow{2}{*}{$\begin{array}{l}\text { No. of transfers } \\
\text { to fresh medium } \\
\text { during I } 8 \text {-day } \\
\text { growth period }\end{array}$} & \multicolumn{7}{|c|}{$\begin{array}{c}\text { Fatty acids* } \\
(\% \text { as methyl esters })\end{array}$} \\
\hline & & $16: 0$ & $16: 1$ & $18: 0$ & I8:I & $18: 2$ & I $8: 3$ & OH-I $8: \mathrm{I}$ \\
\hline \multirow{5}{*}{ Asparagine } & 0 & $20 \cdot 0$ & $I \cdot 6$ & $I \cdot 4$ & $32 \cdot 4$ & $39 \cdot 0$ & $4 \cdot 3$ & $1 \cdot 3$ \\
\hline & I & $19 \cdot 7$ & $I \cdot 2$ & $I \cdot 6$ & $31 \cdot 0$ & $40 \cdot 9$ & 3.9 & $I \cdot 7$ \\
\hline & 2 & 20.4 & I. 6 & $I \cdot 6$ & $31 \cdot 4$ & $39 \cdot I$ & $4 \cdot 6$ & $1 \cdot 3$ \\
\hline & 3 & $19 \cdot 4$ & $\mathrm{I} \cdot 3$ & $\mathrm{I} \cdot 8$ & $32 \cdot \mathrm{I}$ & $40 \cdot I$ & $3 \cdot 6$ & $I \cdot 7$ \\
\hline & 4 & 20.6 & $I \cdot 1$ & $I \cdot 7$ & $29 \cdot 4$ & $4 \mathrm{I} \cdot 4$ & $4 \cdot 4$ & $J \cdot 4$ \\
\hline \multirow{5}{*}{$\begin{array}{l}\text { Aspartic } \\
\text { acid }\end{array}$} & 0 & $20 \cdot 6$ & $\mathrm{I} \cdot 4$ & $5 \cdot 7$ & $2 I \cdot 4$ & $28 \cdot I$ & $\mathrm{I} \cdot 8$ & $2 \mathrm{I} \cdot 0$ \\
\hline & I & $21 \cdot 7$ & $1 \cdot 2$ & 5.9 & 18.6 & $17 \cdot 3$ & $\mathrm{I} \cdot 2$ & $34 \cdot I$ \\
\hline & 2 & $21 \cdot 4$ & $I \cdot 4$ & $3 \cdot 6$ & 19.6 & I9.I & $2 \cdot 2$ & $32 \cdot 7$ \\
\hline & 3 & 20.9 & $I \cdot 2$ & $3 \cdot 8$ & 18.8 & $I 9 \cdot I$ & $I \cdot 4$ & $34 \cdot 8$ \\
\hline & 4 & $22 \cdot I$ & $I \cdot 2$ & $4 \cdot 3$ & $19 \cdot 2$ & 16.9 & 0.8 & 35.5 \\
\hline
\end{tabular}

* Triglyceride fatty acids are given in full in Table $\mathbf{I}$.

Alkaloid. Evidence on aspartic acid medium of an increase in the alkaloid content of transferred colonies with respect to the control was obtained by viewing the base of the agar plates under u.v. light $(350 \mathrm{~nm})$. Quantitative analysis of the mycelial alkaloid confirmed that more was produced (Fig. 4) with increasing number of transfers, although the alkaloid spectrum remained unchanged. Alkaloids were not present in mycelia grown on asparagine medium.

Lipid. The lipid in asparagine colonies increased slightly in amount but remained constant in quality as a result of frequent transfer to fresh medium (Fig. 4, Table 4). On aspartic acid the increase in total lipid was more marked and the proportion of ricinoleate in the triglyceride oil was enhanced, at the expense of linoleate, after only one transfer to fresh medium.

Amino acids. The total 'free' amino acids in mycelia grown on aspartic acid increased with more frequent transfer to fresh medium, while a decrease occurred on asparagine. This was also reflected by the predominant components. The much greater abundance of amino acids in untransferred colonies on asparagine compared with aspartic acid was due to greater concentrations of almost all components. Although lysine made the principal contribution, its concentration decreased with frequency of transfer (Table 5).

Concentrations of the 'peptidyl' amino acids in mycelia grown on asparagine were greater than in aspartic acid colonies, with the exception of lysine which was much reduced (Table 6). The 'peptidyl' lysine of aspartic acid colonies decreased with three or four transfers to fresh medium.

In general, the various changes in 'free' and 'peptidyl' lysine concentrations were mutually compensated, thereby maintaining lysine as the most abundant amino acid, although its predominance was more marked on aspartic acid.

\section{Effect of transfer of mycelia from asparagine to aspartic acid or from aspartic acid} to asparagine media

The fungus required more than $2 \frac{1}{2}$ days of growth on aspartic acid before transfer to asparagine for the colony subsequently, during a total of 18 days' growth, to develop sclerotial tissue containing the usual amount (about $0.1 \%, \mathrm{w} / \mathrm{w}$ ) of alkaloid. However, about 12 days' growth on asparagine was required to ensure that no visible diversion from a sphacelial growth form took place in the remaining 6 days on aspartic acid. Shorter initial 
Table 5. Concentration of 'free' amino acids of 18 -day-old mycelia of C. purpurea strain 29/4D3 transferred to fresh asparagine or aspartic acid agar media

Amino acids (mg/g dry wt)

\begin{tabular}{|c|c|c|c|c|c|c|c|c|c|c|}
\hline \multirow[b]{3}{*}{ No. of transfers } & & & & & & & & & & \multirow{3}{*}{4} \\
\hline & \multicolumn{5}{|c|}{ Aspartic acid } & \multicolumn{4}{|c|}{ Asparagine } & \\
\hline & $\ldots 0$ & I & 2 & 3 & 4 & 0 & $\mathbf{I}$ & 2 & 3 & \\
\hline Asp & $I \cdot 15$ & 0.99 & $I \cdot 20$ & $\mathrm{I} \cdot 3 \mathrm{I}$ & $\mathrm{I} \cdot 57$ & $\mathrm{I} \cdot 24$ & 0.89 & 0.95 & $\mathrm{I} \cdot 28$ & 0.80 \\
\hline Thr, Asn, Gln & 0.29 & 0.25 & 0.30 & 0.51 & $0 \cdot 72$ & $I \cdot 64$ & 0.87 & $I \cdot 00$ & 0.67 & 0.68 \\
\hline Ser & 0.16 & 0.17 & 0.34 & 0.39 & 0.53 & $1 \cdot 06$ & 0.62 & 0.66 & $0 \cdot 74$ & $0.5 \mathrm{I}$ \\
\hline Glu & $I \cdot 66$ & $2 \cdot 03$ & $2 \cdot 04$ & $2 \cdot 10$ & $3 \cdot 35$ & $3 \cdot 93$ & $3 \cdot 68$ & $3 \cdot 33$ & $3 \cdot 95$ & $3 \cdot 42$ \\
\hline Gly & 0.12 & 0.15 & 0.20 & 0.09 & 0.27 & 0.19 & 0.17 & 0.19 & 0.20 & 0.13 \\
\hline Ala & 0.88 & $I \cdot 04$ & 0.85 & 0.87 & I.09 & $\mathrm{I} \cdot 47$ & $I \cdot 62$ & $I \cdot 63$ & $\mathrm{I} \cdot 78$ & $I \cdot 5 I$ \\
\hline Cys & 0.59 & 0.48 & 0.85 & 0.87 & 0.82 & 0.47 & 0.39 & 0.36 & 0.41 & $0.4 \mathrm{I}$ \\
\hline Val & 0.12 & $0 \cdot 19$ & 0.25 & $0.2 \mathrm{I}$ & $0 \cdot 29$ & 0.20 & 0.44 & 0.46 & 0.49 & 0.44 \\
\hline Met & 0.0 & 0.05 & 0.05 & 0.06 & 0.08 & 0.07 & 0.05 & 0.05 & 0.03 & - \\
\hline Ile & 0.13 & 0.15 & 0.23 & 0.17 & 0.17 & 0.53 & 0.45 & 0.60 & 0.55 & $0.5 \mathrm{I}$ \\
\hline Leu & 0.09 & 0.14 & 0.23 & 0.13 & 0.15 & 0.65 & 0.63 & 0.58 & 0.47 & 0.42 \\
\hline Tyr & 0.12 & 0.13 & 0.23 & 0.18 & 0.21 & 0.64 & 0.66 & 0.67 & 0.46 & 0.45 \\
\hline Phe & 0.07 & 0.09 & 0.18 & 0.08 & 0.13 & 0.33 & 0.27 & 0.28 & 0.25 & 0.28 \\
\hline$\gamma-\mathrm{Aba}$ & 0.08 & 0.13 & 0.13 & 0.05 & 0.10 & 0.26 & 0.21 & 0.26 & 0.36 & 0.27 \\
\hline His & 0.14 & 0.13 & 0.14 & 0.15 & 0.13 & 0.29 & 0.28 & 0.32 & $0 \cdot 28$ & 0.24 \\
\hline Lys & $2 \cdot 25$ & $1 \cdot 89$ & $2 \cdot 35$ & I $\cdot 94$ & $3 \cdot 10$ & $12 \cdot 84$ & $I 4: 37$ & $\mathrm{I} 2 \cdot 86$ & $9 \cdot 94$ & $7 \cdot 89$ \\
\hline Arg & 0.26 & 0.27 & 0.45 & 0.30 & 0.50 & 0.26 & I.09 & I.08 & 0.88 & 0.68 \\
\hline $\begin{array}{l}\text { Total 'free' } \\
\text { amino acids }\end{array}$ & $8 \cdot 12$ & $8 \cdot 26$ & $10 \cdot 0$ & $9 \cdot 4$ & $13 \cdot 2$ & $27 \cdot 0$ & $26 \cdot 9$ & $25 \cdot 3$ & $22 \cdot 7$ & I $8 \cdot 6$ \\
\hline
\end{tabular}

Table 6. Concentration of 'peptidyl' amino acids of I8-day-old mycelia of C. purpurea strain 29/4D3 transferred to fresh asparagine or aspartic acid agar media

\begin{tabular}{|c|c|c|c|c|c|c|c|c|c|c|}
\hline \multirow[b]{3}{*}{ No. of transfers } & \multicolumn{9}{|c|}{ Amino acids (mg/g dry wt) } & \\
\hline & \multicolumn{5}{|c|}{ Aspartic acid } & \multicolumn{5}{|c|}{ Asparagine } \\
\hline & $\cdots$ & $\mathbf{I}$ & 2 & 3 & 4 & 0 & I & 2 & 3 & 4 \\
\hline Asp & $13 \cdot 36$ & $15 \cdot 18$ & $\mathrm{I} 2 \cdot \mathrm{I} 4$ & I $2 \cdot 84$ & $13 \cdot 27$ & $2 I \cdot 95$ & $2 I \cdot 33$ & $17 \cdot 8 \mathrm{I}$ & $23 \cdot 3 I$ & $29 \cdot 60$ \\
\hline Thr, Asn, Gln & $9 \cdot 48$ & 10.97 & $9 \cdot 32$ & 13.24 & 13.59 & $12 \cdot 82$ & I I 57 & $12 \cdot 00$ & I $4: 54$ & $16 \cdot 18$ \\
\hline Ser & $8 \cdot 04$ & $8 \cdot 45$ & 6.69 & $7 \cdot 54$ & $7 \cdot 98$ & $12 \cdot 15$ & $10 \cdot 13$ & $9 \cdot 13$ & I2.94 & $15 \cdot 44$ \\
\hline Glu & 16.64 & I 5.48 & $12 \cdot 67$ & $15 \cdot 40$ & $16 \cdot 12$ & $22 \cdot 81$ & 20.90 & 19.45 & $24 \cdot 72$ & $3 I \cdot 58$ \\
\hline Gly & 9.69 & 10.41 & 8.62 & $8 \cdot 40$ & $9 \cdot 28$ & $16 \cdot 78$ & $14 \cdot 78$ & 14.06 & 18.05 & 20.09 \\
\hline Ala & 8.94 & $9 \cdot 6 \mathrm{I}$ & $7 \cdot 76$ & 8.00 & $9 \cdot 12$ & $18 \cdot 23$ & $17 \cdot 27$ & 14.96 & 19.96 & $24 \cdot 20$ \\
\hline Cys & - & - & $\therefore$ & - & - & - & - & - & - & 0.71 \\
\hline Val & 3.96 & $3 \cdot 39$ & $3 \cdot 37$ & $4 \cdot 24$ & $5 \cdot 5 \mathrm{I}$ & $6 \cdot 20$ & $5 \cdot 93$ & $5 \cdot 78$ & $7 \cdot 12$ & $9 \cdot 85$ \\
\hline Met & 二 & - & - & - & - & 0.46 & 0.26 & 0.86 & I. $4 \mathrm{I}$ & $1 \cdot 82$ \\
\hline Ile & $4 \cdot 48$ & $3 \cdot 31$ & $3 \cdot 20$ & $4 \cdot 20$ & $2.8 \mathrm{I}$ & 6.99 & $5 \cdot 77$ & $5 \cdot 68$ & $7 \cdot 62$ & $9 \cdot 58$ \\
\hline Leu & 13.67 & $12 \cdot 16$ & $I I \cdot 9 I$ & $13 \cdot 42$ & 13.49 & 19.21 & 17.98 & $17 \cdot 14$ & 20.59 & 26.00 \\
\hline Tyr & $2 \cdot 21$ & $I \cdot 50$ & $I \cdot 39$ & 0.35 & 3.05 & 3.90 & $\mathrm{I} \cdot 46$ & 4.00 & $5 \cdot$ I I & $7 \cdot 20$ \\
\hline Phe & 5.01 & $5 \cdot 14$ & $4 \cdot 50$ & $4 \cdot 70$ & $5 \cdot 32$ & $7 \cdot 54$ & 8.05 & $7 \cdot 56$ & 9.09 & I I 82 \\
\hline$\gamma$-Aba & - & - & - & - & - & - & - & - & - & 一 \\
\hline His & 2.98 & $2 \cdot 70$ & $2 \cdot 20$ & $2 \cdot 79$ & 3.09 & $4 \cdot 35$ & 3.93 & $3 \cdot 86$ & $4 \cdot 37$ & $5 \cdot 38$ \\
\hline Lys & $42 \cdot 17$ & $49 \cdot 87$ & $43 \cdot 0 \mathrm{I}$ & $38 \cdot 46$ & $35 \cdot 14$ & 23.98 & $18 \cdot 19$ & $15.5 \mathrm{I}$ & I $8 \cdot 58$ & $22 \cdot 37$ \\
\hline Arg & $9 \cdot 24$ & $9 \cdot 18$ & 7.08 & $7 \cdot 76$ & $8 \cdot 57$ & 13.59 & 12.00 & I I 28 & II.47 & I 8.57 \\
\hline $\begin{array}{l}\text { Total 'peptidyl' } \\
\text { amino acids }\end{array}$ & I 49.9 & I $57 \cdot 4$ & 133.9 & $\mathrm{I} 4 \mathrm{I} \cdot 3$ & $146 \cdot 3$ & 190.9 & 169.5 & I $59 \cdot I$ & 198.9 & $250 \cdot 4$ \\
\hline $\begin{array}{l}\text { Total lysine ('free' } \\
\text { + 'peptidyl') }\end{array}$ & $44 \cdot 5$ & $5 \mathrm{I} \cdot 8$ & $45 \cdot 4$ & $40 \cdot 4$ & $38 \cdot 2$ & $36 \cdot 8$ & $32 \cdot 6$ & $28 \cdot 4$ & $28 \cdot 5$ & $30 \cdot 3$ \\
\hline
\end{tabular}



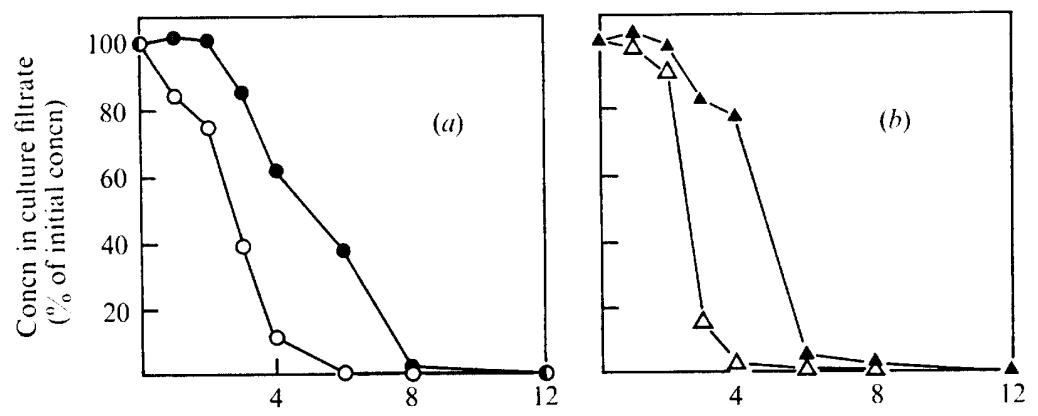

Time after inoculation (days)
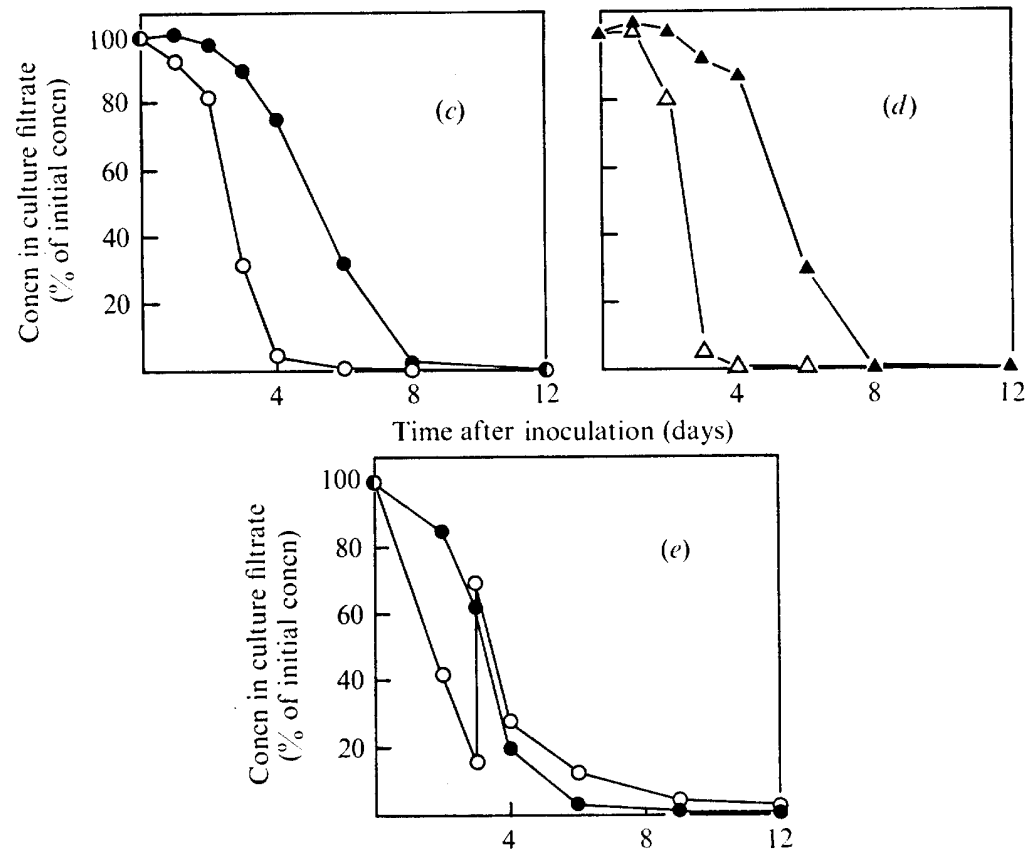

Time after inoculation (days)

Fig. 5. Uptake of asparagine $(\bigcirc)$, aspartic acid $(\bullet)$, glutamine $(\triangle)$ and glutamic acid $(\boldsymbol{\Lambda})$ from liquid media by C. purpurea strain 29/4D3. (a) Asparagine $(0.5 \%$, w/v) or aspartic acid (I \%,w/v) present as the sole nitrogen source. (b) Glutamine $(0.5 \%$, w/v) or glutamic acid (I \%,w/v) present as the sole nitrogen source. (c) Asparagine $(0.25 \%, \mathrm{w} / \mathrm{v})$ and aspartic acid $(0.5 \%, \mathrm{w} / \mathrm{v})$ together. $(d)$ Glutamine $(0.25 \%, \mathrm{w} / \mathrm{v})$ and glutamic acid $(0.5 \%, \mathrm{w} / \mathrm{v})$ together. $(e)$ As $(c)$, with more $(0.13 \%$, w/v) asparagine added at day 3 .

periods of growth on asparagine allowed sclerotial tissue to develop after the colony was transferred to aspartic acid.

\section{Uptake of amino acids from liquid media}

When aspartic acid or glutamic acid was present as the nitrogen source in liquid media their rates of uptake (Fig. 5) indicated an initial 2 day lag which was not apparent with asparagine or glutamine. Thereafter, the rate of uptake of the amides was slower than that of the acids.

When aspartic acid or glutamic acid was mixed with its respective amide the rates of 
uptake (Fig. 5) continued to follow the same pattern so that it appeared that there was preferential uptake of the amide, particularly in a mixture of glutamine and glutamic acid. Fresh asparagine added on day 3 to a mixture of aspartic acid and asparagine did not disturb the pattern of uptake of the acid. Mixtures of aspartic acid and asparagine or of glutamic acid and glutamine supported the production of the sclerotial growth form normally associated with the acid.

The ph value of aspartic acid and glutamic acid media increased from 5.7 to 6.5 after 3 days' incubation, then gradually decreased to 5.5 . In asparagine and glutamine cultures the increase was less marked and the acidity declined to about $\mathrm{pH} 4 \cdot 6$, whereas a mixture of the acid and amide showed an intermediate pattern of $\mathrm{pH}$ change. It was clear that the determination of growth form by the nitrogen source was not mediated through grossly divergent effects on the $\mathrm{pH}$ of the medium.

\section{DISCUSSION}

The present studies have, for the first time, demonstrated that the form in which amino nitrogen is presented to an ergot fungus in axenic culture can determine whether the hyphae will persist in the freely-sporulating sphacelial growth form or differentiate into sclerotial tissue resembling that of the parasitic ergot sclerotium and elaborate the same alkaloids. Furthermore, the ability to control the morphological differentiation of a homokaryotic mycelium has afforded a useful tool by which it is possible to study in vitro the biochemical divergencies of the sphacelial and sclerotial growth forms of one strain of C. purpurea. It has been possible to control the initiation of the differentiation process but there was some delay in the expression of sclerotial characters after transferring to the requisite nitrogen source. The fungus appeared to require about $2 \frac{1}{2}$ days' growth on aspartic acid for the mycelium produced during that period to become 'programmed' to differentiate into the sclerotial growth form. However, at least 5 days' growth on asparagine was necessary for the tissue to resist the subsequent influence of aspartic acid to promote sclerotium formation and remain purely sphacelial. Thus, aspartic acid, though taken up rather more slowly by the fungus, showed a quicker and more dominant influence on differentiation than asparagine. This conclusion applies also to glutamic acid and glutamine.

The extent to which a range of different isolates of $C$. purpurea might show a response similar to that of strain 29/4D3 was investigated. Thirteen out of 30 isolates grown on aspartic acid or glutamic acid agar showed the sclerotial response. Almost all isolates sporulated freely on asparagine. It is clear therefore that while the effects of these amino acids, described here, are not confined solely to the peculiarities of one experimental strain they do not elicit the same pair of divergent responses from all strains. The influence of other amino acids (i.e. alanine, glycine, serine and valine which promoted sclerotial growth of strain 29/4D) on the morphology of these 30 isolates was not determined. However, the present findings suggest, at least in part, a possible mechanism through which the differentiation of sclerotial tissue is controlled. A switch from sphacelial to sclerotial growth is a regular feature of the parasitic pattern of the organism and on which the biosynthesis of ergot alkaloids by this fungus is dependent both in vivo and in vitro. Recent studies on parasitism (Mantle \& Nisbet, I976) have indicated that an amide nitrogen source is available during sphacelial development and that an accumulation occurs of amino acids which promote sclerotium formation, within the infected floret, prior to sclerotial cell formation. It is suggested that the use of media based on aspartic or glutamic acids, and possibly other amino acids which promote sclerotium formation, alone or in combinations, may provide 
the most suitable means for the screening of $C$. purpurea isolates to determine their suitability as potential fermentation sources of ergot alkaloids.

The ability of this homokaryotic strain to accumulate in mycelia, which have been transferred frequently to fresh medium, an amount of alkaloid similar to that of natural sclerotia indicates that alkaloid production does not necessarily depend on heterokaryosis, as suggested by Spalla et al. (1968).

For one of us (L.J.N.), this research was in part fulfilment of the requirements for the Ph.D. degree of the University of London and was supported by a Science Research Council research studentship.

\section{REFERENCES}

Amici, A. M., Minghetti, A., Scotti, T., Spalla, C. \& Tognoli, L. (1969). Production of peptide ergot alkaloids in submerged cultures by three isolates of Claviceps purpurea. Applied Microbiology 18, 464-468.

Corbett, K., Dickerson, A. G. \& Mantle, P. G. (I974). Metabolic studies on Claviceps purpurea during parasitic development on rye. Journal of General Microbiology 84, 39-58.

McLaughin, J. L., Goyan, J. E. \& PaUi, A. G. (1964). Thin-layer chromatography of ergo alkaloids. Journal of the American Pharmaceutical Association 53, 306-310.

MANTLE, P. G. (1967). Emergence and phytopathological properties of a new strain of Claviceps purpurea (Fr.) Tul. on rye. Annals of Applied Biology 6o, 353-356.

MANTLE, P. G. (1969a). Development of alkaloid production in vitro by a strain of Claviceps purpurea from Spartina townsendii. Transactions of the British Mycological Society 52, 38I-392.

MantLe, P. G. (1969b). Studies on Claviceps purpurea (Fr.) Tul. parasitic on Phragmites communis Trin. Annals of Applied Biology 63, 425-434.

MANTLE, P. G. (I975). Industrial exploitation of ergot fungi. In The Filamentous Fungi, Volume I, Industrial Mycology. Edited by J. E. Smith and D. R. Berry. London: Edward Arnold.

Mantle, P. G., Morris, L. J. \& Hall, S. W. (I969). Fatty acid composition of sphacelial and sclerotial growth forms of Claviceps purpurea in relation to the production of ergoline alkaloids in culture. Transactions of the British Mycological Society 53, 441-447.

Mantle, P. G. \& NisBet, L. J. (I976). Parasitic growth and differentiation of Claviceps purpurea. Transactions of the British Mycological Society (in the Press).

Mantle, P. G. \& Tonolo, A. (I968). Relationship between the morphology of Claviceps purpurea and the production of akaloids. Transactions of the British Mycological Society 5I, 499-506.

MoRris, L. J. \& HALL, S. W. (I966). The structure of the glycerides of ergot oils. Lipids $\mathbf{1}, 188-196$.

Morris, L. J. \& Wharry, D. M. (1965). Chromatographic behaviour of isomeric long chain aliphatic compounds I. Thin layer chromatography of some oxygenated fatty acid derivatives. Journal of Chromatography 20, 27.

Spalla, C., Amici, A. M., ScotTi, T. \& Tognoli, L. (I968). Heterokaryosis of alkaloid producing strains of Claviceps purpurea in saprophytic and parasitic conditions. In Fermentation Advances. Edited by D. Perlman. London: Academic Press.

Stoll, A., Brack, A., Hoffmann, A. \& Kobel, H. (I957). Process for the preparation of ergotamine, ergotaminine and ergometrine by saprophytic culture of ergot (Claviceps purpurea (Fr.) Tul) in vitro and isolation of the alkaloids thus produced. U.S. Patent No. 2809920.

Thomas, A. J. (1970). In Automation, Mechanisation and Data Handling in Microbiology, p. 107. Society for Applied Bacteriology, Technical Series No. 4. Edited by A. Baillie and R. J. Gilbert. London: Academic Press.

WAIBLINGER, K. \& GROGER, D. (1972). On the production of ergoline alkaloids and fatty acid composition of the mycelium in submerged cultures of various Claviceps species. Biochemie und Physiologie der Pflanzen B.P.P. $163,468-476$. 